\title{
GRAHAM, Laura R. 2018. Performance de Sonhos - Discursos de imortalidade Xavante
} São Paulo: Editora da USP, 1a ed., 357p.

Renato Athias ${ }^{\mathrm{a}}$

A tradução em português do livro Performing Dreams: Discourses of Immortality among the Xavante of Central Brazil, publicado em 1995, pela Editora da Universidade do Texas (EUA), da antropóloga Laura Graham, chegou ao público brasileiro em 2018, em uma primorosa edição da Ed. da USP. Trata-se de um trabalho de fôlego, com questões importantes sobre o discurso, o mito, a fala e performance, temas atualíssimos ampliando a produção antropológica sobre povos indígenas do Brasil. Certamente, esta tradução estava muito esperada para os leitores em português, que trabalham com as populações indígenas do Brasil Central. A pesquisa etnográfica foi entre os Xavante e aconteceu na terra indígena Pimentel Barbosa, realizada entre os anos de 1981 a 1991, com várias vindas da autora ao campo para coletar um

a Professor Associado da Universidade Federal de Pernambuco. Email: renato. athias@ufpe.br. 
conjunto significativo de dados etnográficos que permitiram a escrita deste importante livro que amplia a literatura sobre os povos Xavante.

Laura Graham trabalhou com vários colaboradores, entre os quais o xavante Warodi, filho do famoso Apöw'ë, que estabeleceu contato em 1940 com o SPI. Ela nos esclarece na introdução (p. 44-46), que desde 1981, até o seu falecimento, em 1988, manteve uma relação privilegiada com Warodi, e com os membros de seu grupo de parentesco. Com essas informações ainda na introdução ela nos revela com detalhes os aspectos sua entrada e permanência na área, descrevendo nesta parte as estratégias metodológicas de sua pesquisa, informando, sobretudo, o processo de colaboração (p. 46-53) que conseguiu manter com os Xavantes de Pimentel Barbosa. "Aos poucos fui me dando conta de quão imensa era a vontade de Warodi de compartilhar seu conhecimento do mundo e da criação comigo" (p. 53). Essa é a frase que a autora dá início a uma grande explicação sobre os 'discursos de imortalidade' colocando assim as bases do que chamou de trabalho colaborativo desenvolvido no conjunto do livro.

O capítulo dois coloca o leitor em frente da realidade histórica, social e política dos Xavante. É uma narrativa onde os acontecimentos evidenciados são aqueles que proporcionam mostrar o contato com a sociedade nacional. Esses eventos estão bem distribuídos, em todo o capítulo, de uma forma, que dá conta do período em que autora esteve na área indígena, e Pimentel Barbosa torna-se, na realidade, o centro dessa narrativa. Os Xavante são vistos pelo olhar dos Xavante de Pimentel Barbosa, e bem especificamente da perspectiva de Warodi. Particularmente interessante como a história é descrita pela autora, proveniente de um canto de Warodi que transmite um sonho de seu encontro com os 'criadores' registrado em 1984, precisa a autora. "Continuar como Xavante é continuar habitar o mundo criado pelos imortais para os Xavante...." (p. 59). Evidentemente, nesse capitulo repleto de dados etnográficos sobre as mobilidades e migrações dos Xavante em seu território tradicional, são postas as bases da identidade Xavante e a relação deste com os 'primeiros criadores' e com os 
Xavante atuais. A leitura é agradável e vai pontuando as migrações internas, os conflitos, as cisões, as relações com os não-xavante e uma descrição dos diversos lugares onde os Xavante vivem. Os dados demográficos coletados na época dá, assim, condições para entender a mobilidade atual dos Xavante e uma compreensão de uma geopolítica Xavante. Este capítulo encera dando um apanhado geral dessa geopolítica, mostrando de fato em suas mobilizações e interação com as instituições não-governamentais e governamentais durante os anos noventa (p. 100-108).

Ainda com as orientações de Warodi a autora, no capítulo três, apresenta de uma maneira bem dialógica uma tipologia dos sons, dos cantos e dos sonhos Xavante, para uma compressão ampla e geral, do que se poderia chamar de uma taxionomia sonora e performática xavante. Os sons provenientes dos sonhos e das relações de parentesco fazem parte de uma organização social onde o canto é central no relacionamento interno e a autora é muito feliz em mostrar essa etnografia juntamente com uma interpretação tipológica sobre esses sons. Maravilhosas são as descrições sobre os padrões de residência e os modelos xavante das relações interpessoais próprias de cada um dos grupos de parentesco que se relacionam entre si nesse emaranhado de sons, onde a força da oratória, o discurso e prática performática que mostram os sinais de maturidade, de gênero e afetividade, complementando com todas as suas nuances diurnas e noturnas que são centrais na compreensão das afetividades, individualidade e identidade xavante, marcados para além dos Da-Nho'rè, os cantos coletivos, que fundamentam o ciclo ritualístico. É um capitulo onde a autora busca organizar uma tipologia das palavras públicas sonorizados pelos Xavante de Pimentel Barbosa.

Esta tipologia organizada, descrita e bem fundamentada no terceiro capítulo, está dissecada e amplamente desenvolvida nos capítulos quatro e cinco, quando a autora trata especificamente de mostrar através uma argumentação bem produzida, com base a uma sólida literatura antropológica, sobre o discurso e a metáfora, as bases para 
a sua etnografia sonora, antropologia da música xavante, que dá conta de uma ampla compreensão sobre toda uma relação com a alteridade. É a partir dessas narrativas que as oposições identitárias são delineadas. Os fatos sonorizados dão ênfase também a uma rivalidade que pode ser também ritualizada em diferentes performances em diferentes tempos. Em outras palavras, a autora nos mostra, que os sons, as músicas os cantos, os sonhos marcam a forma xavante de relacionar com o outro. É a partir das expressões sonoras, da própria fala, que o Xavante vai entender o outro com o qual mantém relação, seja o outro Xavante e/ou outro não-xavante.

No capítulo seis sobre a etnografia da fala a autora busca aprofundar sua análise antropológica apoiando-se em vários autores, muito bem documentado, tais como I. Goffman, C. Lévi-Strauss, M. Bakhtin, J. Habermas, E. Benveniste, G. Bateson, R. Sherchner, G. Rouget, P. Stoller, M. Silverstein, D. Maybury-Lewis e A. Seeger entre os principais, para levantar as questões fundamentais que surgem de sua etnografia, e sobre a performance da fala, o discurso público, a interpretação e representação mitológica entre os Xavante de Pimentel Barbosa. Nesse sentido, a centralidade da discussão está na seguinte frase "Warodi referiu-se aos imortais e a si próprio como 'nós' (wa) [...] inserindo-se, assim, na coletividade dos imortais", onde a autora analisa com todos os detalhes do canto na parte ela denomina de 'Eu dos criadores'. Nessa parte, a autora junta a performance da fala com a interpretação dos mitos fundantes, presentes no discurso sobre a imortalidade é reproduzida no Warã, pátio da aldeia. Evidentemente, essa interpretação faz parte do conjunto da linguagem performática discutida nesta parte do livro. Aqui a autora está muito mais interessada em analisar exatamente como os sonhos e os mitos tornam-se uma linguagem em todos os sentidos. A tecnologia existente de gravação e registro entra nesse capítulo como uma necessidade de manter a identidade até mesmo o sigilo dessa identidade musical e de preservar a originalidade, que outrora era repetida pelos criadores. Hoje as testemunhas são trazidas pelos cantos gravados, o som dos outros e que 
vai entrar em uma ação dialógica com cantos e sonhos da pessoa que canta. A tecnologia de registro busca preservar a linguagem expressa dos mitos e dos sonhos falada pelos especialistas no pátio da aldeia.

'A performance do sonho' é o título do livro e do capitulo sete onde a autora busca consolidar a sua análise do encanto e do canto público de Warodi, novamente aqui está posta uma clara relação da performance da fala no presente e a sua relação com a narrativa mitológica dos criadores, com o próprio Warodi, onde os discursos se confundem em uma criatividade atualizada de falas provenientes de outras dimensões temporais (e mitológicas), enfatizando assim a transformação da narrativa e a performance do canto público. Este capítulo é muito rico na análise dos sonhos que viraram cantos de Warodi e na descrição de como essas falas foram ampliadas com uma audiência atenta sobre em cada frase, de cada fala e respostas cantadas de homens adultos e anciãos numa performance dialógica no grupo e no centro da aldeia. Esse diálogo é muito retratado no Epílogo do livro quando Laura, anos depois de sua pesquisa segue um outro cantador que teria escutado e atuado com os toantes de Warodi e, que possuía também uma performance ao cantar e se relacionar com os demais da aldeia alçando um lugar de destaque entre os sabedores. Uma das questões que esse epílogo traz está justamente relacionada com as relações entre o antropólogo, a aldeia, o colaborador e, sobretudo, com o material digital coletado em sua pesquisa de campo. Esta relação entre esses 'lados' cuja a descrição se encontra muito bem relatada nessa parte do livro a autora termina sua narrativa com essas questões abertas produzindo debate os antropólogos que constituem acervos digitais de memória e performances toantes/cantos de um grupo indígena específico.

O livro traz em seus anexos uma riqueza singular. Alguns dos principais cantos Warodi foram passados para uma partitura musical realizada pelo músico T. M. Scruggs, com as anotações gráficas particulares que identifica esse grupo de Xavante e, um maravilhoso CD contendo 39 toantes, cantos de um registro musica impecável reali- 
zado durante a pesquisa de campo da autora. Desta forma a autora transforma o livro em tipo de áudio-book bem peculiar em que os cantos de Warodi chegam, desta vez, definitivamente a esta geração atual, que seguramente vai fazer uso nas enormes discussões promovidas no Warã.

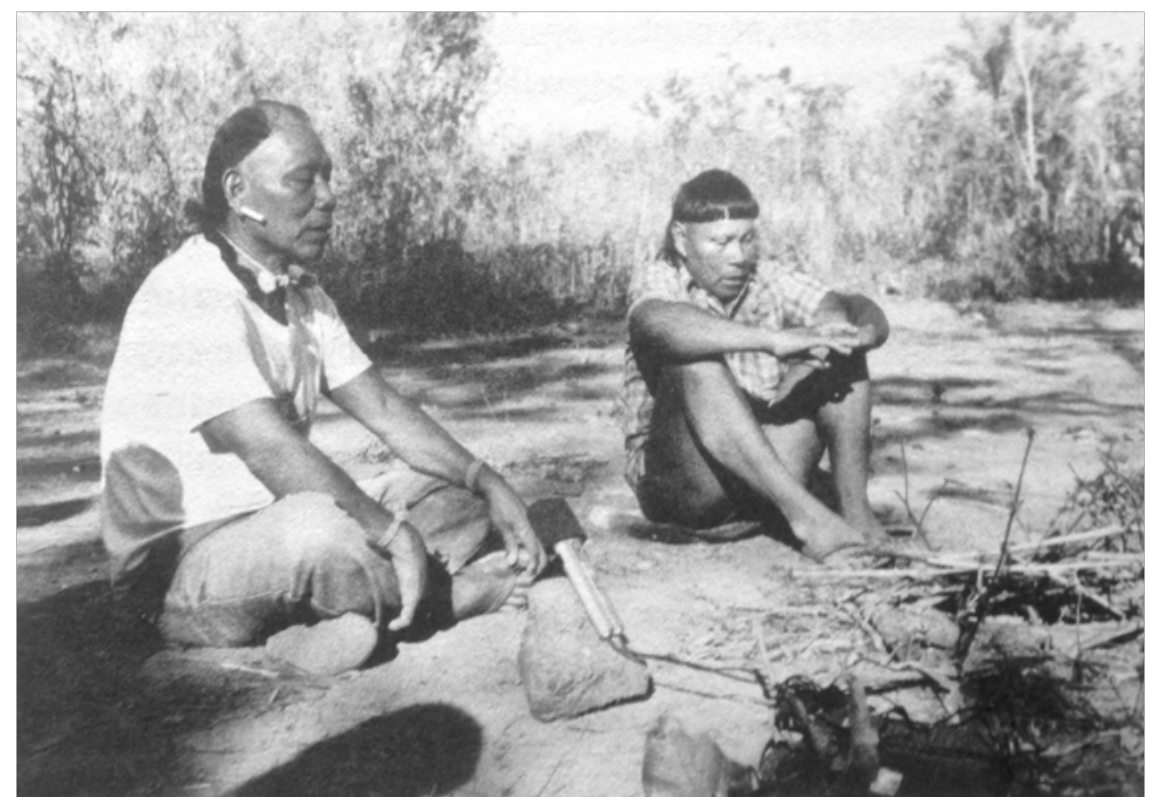

Imagem - No Warã, em uma clareira na mata, Warodi está sentado à esquerda, contando seu sonho aos velhos. A sua esquerda está Ẽtepa.

Fotografia: Laura Graham, 1984.

Recebido em outubro de 2018.

Aprovado em janeiro de 2019. 